\title{
A reforma psiquiátrica no Brasil: uma (re) visão
}

\author{
The psychiatric reform in Brazil: a (re)view
}

AliceHirdes ${ }^{1}$

${ }^{1}$ Universidade Luterana do Brasil, Unidade Universitária de Gravataí. Av. Itacolomi 3.600, São

Vicente. 94170-240

Gravataí RS.

alicehirdes@gmail.com
Abstract This paper aims at contextualizing the Brazilian Psychiatric Reform by reviewing theoretical and practical milestones in the country's policies. Theses, dissertations, papers published in a database (Scielo), books on the theme, and official documents (conference reports, laws, bills) published between 1990 and 2007 werestudied. Theresultsshow the advances and challenges of the Psychiatric Re form and point to the immediate need of a program for qualifying personnel; theneed to useprimary care, mainly the Family Health Program; the need to finance primary care; the adoption of the principles of the psychiatric reform; the need to individualize treatment, psychosocial rehabilitation; integrated care; and therapeutic project constructed collectively through the use of interdisciplinary and trans-disciplinary approaches, as well as constant assessment of the current practices. It is also pointed out that Re form projects are not homogeneous, i. e., practices happen according to the professionals' theoretical conception. This means that there are general guidelines, but that they are subordinated to the specific settings where the practices are carried out.

Key words M ental health, Primary care, M ental health services, Rehabilitation, Rehabilitation centers, Health services evaluation
Resumo Este artigo tem por objetivo contextualizar a reforma psiquiátrica brasileira, a partir da re visão dos marcos políticos, teóricos e práticos. Foram pesquisadas dissertações, teses, artigos em bases dedados (Scielo), livros sobrea temática edocumentos oficiais (relatórios de conferências, leis, portarias) de 1990 a 2007. Osresultados evidenciam osavanços edesafios da reforma psiquiátrica, apontam para a necessidade urgenteda capacitação dosoperadores, a utilização da atenção básica, particularmente a estratégia do Programa de Saúde da Família; o financiamento da atenção básica; a adoção dos princípios da reforma psiquiátrica; a articulação tratamento, reabilitação psicossocial; clínica ampliada; projetos terapêuticos individualizados, construídos coletivamente, mediante abordagens inter/transdisciplinares; ea avaliação das práticas em curso. Finaliza apontando que os projetos de reforma não são homogêneos, as práticas são executadas conforme a concepção teórica dos trabalhadores de saúde mental, ou seja, existem princípios orientadores gerais, mas que, em última análise, estão subordinados aos settings específicos onde ocorrem as práticas. Palavras-chave Saúde mental, A tenção primária à saúde, Serviços de saúde mental, Reabilitação, Centros de reabilitação, Avaliação de serviços de saúde 
Introdução

Marcos políticos, teóricos e práticos

A superação do modelo manicomial encontra ressonância nas políticas de saúde do Brasil que tiveram um marco teórico e político na 8 a Conferência Nacional deSaúde (1986), na 1a Conferência N acional de Saúde M ental (1987), na 2a Conferência Nacional de Saúde M ental (1992), culminando na 3ạ ConferênciaN acional deSaúdeM ental (2001). Observa-se, na reforma psiquiátrica brasileira, nas últimas décadas, intercalação de períodos de intensificação das discussões e de surgimento de novos serviços e programas, com períodos em que ocorreu uma lentificação do processo. Historicamente, podemos situar as décadas de 1980 e 1990 como marcos significativos nas discussões pela reestruturação da assistência psiquiátrica no país.

Um marco histórico para o setor desaúdemental, possibilitador de mudanças ao nível do M inistério da Saúde, foi a Conferência Regional para a Reestruturação da Assistência Psiquiátrica, realizada em Caracas, em 1990. Nesteencontro, no qual - Brasil foi representado e signatário, foi promulgado o documento final intitulado "Declaração de Caracas". Nele, os países da América Latina, inclusive o Brasil, comprometem-sea promover a reestruturação da assistência psiquiátrica, rever criticamente o papel hegemônico e centralizador do hospital psiquiátrico, salvaguardar os direitos civis, a dignidade pessoal, os direitos humanos dos usuáriose propiciar a sua permanência em seu meio comunitário ${ }^{1}$.

Em 2005, foi retomada a "D eclaração de Caracas" sob a forma de um documento intitulado "Princípios Orientadores para o Desenvolvimento daAtenção em Saúde M ental nas Américas", a Carta de Brasília, com o objetivo de avaliar os resultados obtidos desde 1990. Neste documento, os organizadores reconhecem os avanços que se produziram nos últimos quinze anos na reestruturação da atenção psiquiátrica, constatam que existem experiências exitosas desenvolvidas em vários países, assim como obstáculos e dificuldades. Reafirmam a validade dos princípios contidos na "D eclaração de Caracas" em relação à proteção dos direitos humanos e de cidadania dos portadores de transtornos mentais e a necessidade da construção de redes de serviços al ternativos aos hospitais psiquiátricos. Advertem para o aumento da vulnerabilidade psicossocial e das diferentes modalidades de violência. Convocam todos os atores envolvidos para a implementação dos princípios éticos, políticos e técnicos da "D eclaração de Caracas".
Como marcos práticos de reversão do modelo manicomial, podemos citar a intervenção na Casa de Saúde Anchieta, em Santos, o Centro de Atenção Psicossocial Dr. Luís da Rocha Cerqueira, ambos localizados em São Paulo, e o Centro Comunitário de Saúde M ental de São Lourenço do Sul, Rio Grande do Sul, conhecido como "Nossa Casa”. Nicácio ${ }^{3}$, Bezerra Júnior ${ }^{4}$ e Aguiar ${ }^{5}$ consideram a intervenção na Casa de Saúde Anchieta, em Santos, em 1989, um marco na história da psiquiatria brasileira, por se tratar de uma experiência inovadora, em que ocorreu uma intervenção médicolegal num asilo. Esta pode ser considerada a primeira experiência concreta de desconstrução do aparato manicomial no Brasil, e de construção de estruturas substitutivas.

A partir destes marcos, passou-se a privilegiar a criação de serviços substitutivos ao hospital psiquiátrico, quais sejam: redes de atenção à saúde mental, Centros de Atenção Psicossocial (CAPS), leitos psiquiátricos em hospitais gerais, oficinas terapêuticas, residências terapêuticas, respeitandose as particularidades e necessidades de cada local. As iniciativas dos municípios, em que pese a vontade política dos gestores municipais, passaram a ser ressarcidas através das portarias ministeriais, objetivando o deslocamento dos recursos para modalidades alternativas à internação psiquiátrica e compatibilizando os procedimentos das ações de saúde mental com o modelo assistencial.

No Rio Grande do Sul, um marco político importante foi a aprovação da Lei da Reforma Psiquiátrica, a Lei Estadual no 9.716, em 1992, que trata da reforma psiquiátrica em âmbito do estado, enquanto a Lei $n-10.216$, que trata da reforma psiquiátrica em âmbito nacional, foi sancionada no dia 06 de abril de 2001, quase dez anos depois ${ }^{6}$. O M inistério da Saúde igual mente iniciava, na década de 1990, a emissão de uma vasta legislação que viria a nortear todas as ações no sentido de tratar adequadamente as pessoas acometidas de doenças mentais. Deste modo, passados mais de dez anos, o processo de implantação da reforma psiquiátrica deveria encontrar-se em plena consolidação, em todo o paíse, em especial, no Rio Grande do Sul ${ }^{7}$.

Entretanto, o Rio Grande do Sul, um estado pioneiro na aprovação de uma legislação específica na área, e detentor do maior número de CAPS por estado, apresenta diferenças regionais importantes na estruturação de serviços ${ }^{8}$. Enquanto a metade sul protagonizou experiências inéditas de desinstitucionalização, o norte apresenta carência na estruturação de serviços e na inserção das ações de saúde mental nos serviços gerais de saúde. Esta 
realidade descortina-seem outros estados eregiões brasileiras.

\section{Aspectos conceituais}

O termo desinstitucionalização significa deslocar o centro da atenção da instituição para a comunidade, distrito, território. Este termo tem sua origem no movimento italiano de reforma psiquiátrica. Para Rotelli e colaboradores ${ }^{9}$, o mal obscuro da psiquiatria está em haver separado um objeto fictício, a "doença", da "existência global complexa e concreta" dos pacientes e do corpo social. Sobre esta separação artificial se constrói um conjunto de aparatos científicos, legisladores, administrativos ( precisamente a "instituição"), todos referidos à "doença".

A desinstitucionalização tem uma conotação muito mais ampla do que simplesmente deslocar o centro da atenção do hospício, do manicômio, para a comunidade. Enquanto este existir como realidade concreta, as ações perpassarão, necessariamente, por desmontar este aparato, mas não acabam aí. Para o autor acima referido e também ator do processo, é o conjunto que é necessário desmontar (desinstitucionalizar) para o contato efetivo com o paciente na sua "existência" doente.

Rotelli ecolaboradores ${ }^{9}$ nos fazem ver queconcretamente se transformam os modos nos quais as pessoas são tratadas (ou não tratadas) para transformar o seu sofrimento, porquea terapia não émais entendida como a perseguição da solução - cura [...] o problema não é a cura (a vida produtiva), mas a produção de vida, de sentido, de sociabilidade, a utilização das formas (dos espaços col etivos) de convivência dispersa.

Amarante ${ }^{10}$ traça três formulações importantes de desinstitucionalização, a saber: a desinstitucionalização como desospitalização, a desinstitucionalização como desassistência e, por último, a desinstitucionalização como desconstrução. Esta última, abordada acima, nas ponderações de Rotelli e outros ${ }^{9}$. A compreensão e distinção é fundamental para a compreensão do processo e, deacordo com Amarante, irá determinar a forma delidar prático e teórico com a desinstitucionalização.

\section{A desinstitucionalização}

como desospitalização

A noção de desinstitucionalização surge nos Estados Unidos, no governo Kennedy, mas seus princípios e as medidas adotadas são basicamente dedesospitalização. N esta modalidade, há uma crítica ao sistema psiquiátrico, na centralização da atenção na assistência hospitalar, mas não é questionado o saber que o legitima. Esta configuração está baseada e construída a partir dos projetos de psiquiatria preventiva e comunitária. Para Amarante ${ }^{10}$, "a desinstitucionalização nesta tradição está voltada principalmente para objetivos administrativos (redução dos custos da assistência para os cofres públicos) e menos para uma real transformação da natureza da assistência". Este autor coloca, também, que o hospital psiquiátrico não équestionado nesta formulação de desinstitucional ização.

A desinstitucionalização

como desassistência

Para Amarante, alguns setores entendem a desinstitucionalização como desospitalização, ou, ainda, como desassistência - abandonar os doentes à própria sorte. 0 autor considera que neste rol estão incluídos determinados segmentos atavicamente conservadores, resistentes a qualquer idéia sobre direitos de grupos minoritários. Há, ainda, um grupo que tem interesses econômicos em jogo e opõeseà desinstitucionalização em virtudedos interesses constituídos. Coloca que a tendência contra-desinstitucionalizante assume maior magnitude após o Projeto de Lei Paulo Delgado - 3.657/89, quepropõe a substituiçãa progressiva dos hospitais psiquiátricos por outras modalidades de assistência.

\section{A desinstitucionalização}

como desconstrução

De acordo com Amarante, esta tendência está caracterizada pela crítica epistemológica ao saber médico constituinte da psiquiatria. É nesta tendência que o movimento pela reforma psiquiátrica brasileira se inspira. E este movimento, por sua vez, identifica-se com a trajetória de desinstitucionalização prático-teórica desenvolvida por Franco Basaglia, na Itália. No final da década de 1970, as idéias de Basaglia chegam ao Brasil, sobretudo em virtude da repercussão internacional do processo italiano que englobou a desativação do hospital de Gorizia, a criação da "psiquiatria democrática" e de "redes alternativas à psiquiatria"e, posteriormente, a promulgação da Lei 180 na Itália, conhecida como Lei Basaglia.

Amarante compara o movimento pela reforma sanitária com o movimento pela reforma psiquiátrica. O bserva quea reforma sanitária, de uma perspectiva inicial de crítica quanto à natureza do saber médico, torna-se um conjunto de medidas de cunho administrativo, sem o questionamento das abordagens técnicas centradas quase exclusivamente em sintomas, no especialismo, na cultura medicalizante eno intervencionismo diagnóstico e terapêutico. Considera que o movimento pela re forma psiquiátrica foi além, porque busca trans- 
formações qualitativas no modelo de saúde e não meramente de reorganização administrativa.

Para Amarante ${ }^{10}$, a produção de Basaglia foi e continua sendo um marco importante de referência para os projetos de reforma psiquiátrica e para o redimensionamento atual da desinstitucionalização em psiquiatria. Coloca que "o projeto de desinstitucionalização volta-se para a superação do ideal de positividade absoluta da ciência moderna em sua racionalidade de causa e efeito, para voltarse para a invenção da realidade enquanto um processo histórico" ${ }^{10}$.

Princípios para a organização dos serviços

A seguir, citamos os princípios de Rotelli ${ }^{9}$ para um trabalho efetivo de desinstitucionalização. Pensamos que estes indicam um caminho norteador, que deveria estar presente na prática dos serviços desaúdemental e, periodicamente, deveria ser consultado, para corroborar a prática executada com a teoria ever sehá congruência e pertinência entreo desenvolvido e 0 anunciado.

Rotelli ${ }^{9}$ vê a desinstitucionalização como um trabalho prático de transformação que contempla: a ruptura do paradigma clínico e a reconstrução da possibilidade - probabilidade; o deslocamento da ênfase no processo de "cura" para a "invenção de saúde"; a construção de uma nova política de saúde mental; a centralização do trabalho terapêutico no objetivo de enriquecer a existência global; a construção de estruturas externas totalmente substitutivas à internação no manicômio; a não-fixação dos serviços em um modelo estável, mas dinâmico e em transformação; a transformação das relações de poder entre a instituição e os sujeitos; o investimento menor dos recursos em aparatos e maior nas pessoas.

Além destes aspectos, 0 autor refere o cuidado como elemento-chave para transformar os modos de viver esentir o sofrimento do "paciente" em sua concretude, no cotidiano; a mobilização de todos os atores envolvidos - técnicos e pacientes -, isto irá produzir comunicação, solidariedade e conflitos, ingredientes fundamentais para a mudança das estruturas e dos sujeitos; a promoção da capacidade de auto-ajuda e de autonomia das pessoas; 0 enriquecimento das competências profissionais e dos espaços de autonomia e decisão; a demolição da compartimentalização das terapias (médica, psicológica, social, farmacológica, etc.); a valorização da dimensão afetiva na relação terapêutica, de figuras não profissionais no campo, utilização de esforços sociais e; a liberdade é terapêutica?.

Dentre os princípios para a organização dos serviços de saúde mental, traz a necessidade do deslocamento essencial da perspectiva da intervenção dos hospitais psiquiátricos para a comunidade; o deslocamento do centro do interesse somente da doença para a pessoa e para a sua desabilidade social e o deslocamento de uma ação individual para uma ação coletiva nos confrontos dos pacientes com seus contextos ${ }^{9}$.

Pela inquestionável importância que assume a produção prático-teórica basagliana, estas idéias e conceitos deverão sempre estar presentes no cotidiano dos trabalhadores de saúde mental que se espelham nos pressupostos da reforma psiquiátrica. I gualmente, pensamos que estes conceitos devem ser uma linguagem universal, acessível a todos os profissionais, técnicos e não-técnicos. I sto evitaria as "derrapagens" eventuais que porventura possam ocorrer.

O projeto de desinstitucionalização busca a reconstrução do objeto (enquanto sujeito histórico) que o modelo tradicional reduziu e simplificou (causalidade linear doença/cura - problema/solução). M as para al cançar este objetivo, faz-se necessário que as novas instituiç̃ões estejam à altura do objeto que está em constante reconstrução na sua existência - sofrimento: esta éa base da instituição inventada?.

Os projetos de atendimento surgidos nos últimos anos têm de saída a recusa do modelo sintomático em benefício da criação de uma clínica psiquiátrica renovada, deslocando o processo do tratamento da figura da doença para a pessoa doente. N estes novos espaços, as ações antes centradas nos sinais e sintomas, na classificação dos diferentes quadros nosográficos, em suma, na medicalização da loucura, passam a ter outro enfoque, que é o de falar de saúde, de projetos terapêuticos, de cidadania, de reabilitação e reinserção social e, sobretudo, de projetos de vida ${ }^{11}$.

\section{Os Centros de Atenção Psicossocial e demais serviços substitutivos}

De acordo com dados do M inistério da Saúde, existem no país 918 CAPS em funcionamento, 120 deles voltados, exclusivamente, ao atendimento de dependentes de álcool e drogas. Os CAPS, os 475 serviços residenciais terapêuticos e os 350 ambulatórios, ao lado dos 36 Centros de Convivência e Cultura e do Programa de Volta para Casa e Inclusão Social pelo Trabalho, compõem a rede extrahospitalar que substitui, aos poucos, 0 atendimento prestado pelos hospitais psiquiátricos, no Brasi $\left.\right|^{12,13}$.

0 maior número de CAPS por 100 mil habitantes localiza-se na Região Sul - Rio Grande do 
Sul, Santa Catarina e Paraná, seguidos pela Região Sudeste - São Paulo, Rio de Janeiro, M inas Gerais eEspírito Santo. As regiões Sudeste e N ordeste detêm, ainda, o maior número de hospitais psiquiátricos. 0 estado do Amazonas é o único estado brasilei ro sem nenhuma referência de rede $\mathrm{e}^{12}$.

Apesar de os hospitais psiquiátricos consumirem $88 \%$ dos recursos orçamentários do SUS destinados à saúde mental, e do relatório da III Conferência Nacional de Saúde M ental prever que até 0 ano 2004 fossem extintos todos os leitos em hospitais psiquiátricos no Brasil, consolidando o projeto "Por uma Sociedade sem M anicômios", através da estruturação de uma rede substitutiva de saúde mental, a realidadenacional que se descortina ainda contempla o hospital psiquiátrico. Cabe destacar que os investimentos nos serviços substitutivos vêm aumentando desde 2004. A reorientação do modelo assistencial em saúde mental demanda investimentos políticos, técnicos, financeiros e éticos, entre outros, assim como a articulação com outras instâncias - educação, trabalho, cultura, habitação e habilitação profissional, objetivando a cidadania, a emancipação ${ }^{12-15}$.

Bichaff ${ }^{16}$ investigou o processo de trabal ho nos CAPS, tomando por base 0 atual momento da reforma psiquiátrica no Brasil. Os resultados apontam que os trabalhadores apresentam uma trajetória deformação profissional tradicional, as ações sendo norteadas, fundamentalmente, por concepções coerentes com o modelo hegemônico, cujo objeto de trabalho é o indivíduo e sua doença. A análise evidencia também que as relações entre 0 saber e o fazer resultam em práticas eintervenções tradicionais. A autora conclui que as ações que estariam dirigidas ao contexto concreto de vida desses usuários, além de pouco representativas, estão fundamentadas no conhecimento advindo da própria prática e do senso comum. 0 estudo mostra a necessidade de revisão dos processos de trabalho da equipe, para possibilitar a construção de novos saberes, instrumentos e práticas, bem como 0 envolvimento dos trabal hadores enquanto atores sociais da reforma.

O utra pesquisadora, Oliveira ${ }^{17}$, investigando a mesma temática, o processo de trabalho das equipes de saúde mental nos serviços extra-hospitalares de atenção à saúde mental, aponta que a cidadania é dissociada da vivência e organização do trabalho de profissionais e usuários. A referência de cidadania predominante nos processos de trabalho foi a cidadania tutelada. 0 estudo destaca ainda que não são exploradas as contradições das práticas que os profissionais operam: si imultaneamente restrição de liberdade e aten ção psicossoci- al; alienação dos mesmos em relação ao seu trabaIho, sen do a medicalização o mecanismo estruturante de todas as práticas analisadas e os instrumentos mais evidentes na abordagem terapêutica.

Arejano ${ }^{18}$, analisando as relações de poder nos serviços de saúde mental, entende que a discussão sobre o processo da reforma está centrada principalmenteno caráter administrativo, sendo as questões técnicas, éticas e políticas contempladas por uma pequena parcela dos trabalhadores. A autora realizou o seu estudo na Pensão Pública Protegida "Nova Vida", de Porto Alegre, uma moradia temporária para pessoas portadoras de sofrimento psíquico que precede a aprovação da Lei no 9.716 da reforma psiquiátrica do estado do Rio Grande do Sul. Conclui que a instrumentalização do fazer em saúde mental é construída no cotidiano, observa que o comprometimento dos trabal hadores com o processo de reforma deriva de uma questão mais pessoal, do que propriamente de conhecimento histórico-político do processo. 0 estudo aponta para a necessidade urgente da criação de estratégias de cuidado em saúdemental aliadas aos princípios da legislação; constata uma lacuna entre um referencialteórico arcaico e um novo referencial, ainda incipiente na sua ação prática.

Os estudos anteriormente citados trazem à tona a questão da instrumentalização dos operadores para a mudança do paradigma. Os novos serviços necessitam de profissionais capacitados para operar dentro de novas estratégias. 0 processamento de mudanças em nível de reformulação do modelo de assistência não se dará somente através de medidas de cunho legislativo, mas fundamentalmente pelas rupturas realizadas nos microespaços e através da desconstrução do modelo manicomial fortemente arraigado nos profissionais e no senso comum. Deacordo com Saraceno ${ }^{19}$, as experiências de transformação da assistência psiquiátrica no que chama de sul do mundo (entendemos que estamos situados neste contexto), são "inventadas" e obtidas da conjugação da pobreza de recursos institucionais associada à capacidade deidentificar recursos da comunidade.

Para Saraceno ${ }^{19}$, a história natural das doenças encontra a história natural dos serviços. Assinala a importância da revisão e crítica dos serviços para as transformações efetivas na vida dos pacientes, uma vez que estas variáveis - os serviços - têm um peso significativamente mais importante do que as variáveis clínicas. 0 autor ressalta que um serviço de alta qualidade deverá ser permeável e dinâmico, com uma alta integração interna e externa.

Saraceno ${ }^{19}$ enfatiza que "a organização (seja em termos de acesso da demanda, seja em termos da 
não-estereotipia da resposta) orientada às necessidades do pacientee não às do serviço". A integração interna dos serviços não pode estar voltada para a burocratização estandardizada dos próprios procedimentos, mas antes, centrada às especificidades decada pessoa. A integração externa éreferida como a permeabilidade do serviço a saberes e recursos existentes que circundam estes saberes e recursos. Esta permeabilidade não se restringe somente aos recursos disponíveis, mas a sua concreta ativação. 0 autor entende que os muros a serem demolidos são aqueles que impedem a utilização de outros saberes e recursos.

Os serviços constituem-se, para Saraceno ${ }^{19}$, como a variável que influi no processo reabilitativo. Assinala que somente serviços de alta qualidade podem garantir programas reabilitativos confiáveis. Dentre as características de um serviço de alta qualidade, identifica aquelas que se ocupam de todos os pacientes e a todos oferecem possibilidades dereabilitação. Pontua que os serviços quenão oferecem estas possibilidades acabam gerando hierarquias de intervenção e, os menos dotados, acabam sendo excluídos do processo. Além desta característica, Saraceno ressalta que um serviço de alta qualidade deverá ser permeável e dinâmico, com uma alta integração interna e externa: "um serviço onde a permeabilidade dos saberes e dos recursos prevalece sobre a separação dos mesmos".

Neste sentido, as abordagens a partir de uma perspectiva transdisciplinar permitem uma multiplicidade de intervenções no processo de trabalho que favorecem a "reformulação ampliada do trabalho em saúde" ${ }^{20}$, ou clínica ampliada ${ }^{21}$ e 0 trabalho vivo em saúde $e^{22,23}$. 0 paradigma da saúde mental, o deslocamento das práticas para a comunidade, o campo psicossocial remetem ao entre cruzamento de saberes e práticas que não pode se dar pela soma de disciplinas conexas, mas através de uma redefinição da transdisciplinaridade.

Para Almeida Filho ${ }^{24}$, não são os campos disciplinares que interagem entre si, sendo construídos na prática científica cotidiana através dos sujeitos que atuam como agentes institucionais representativos. Uma das problemáticas daí decorrentes diz respeito ao fato dequeas relaçõestransdisciplinares em princípio tendem mais para o conflito do que para o diálogo. 0 enriquecimento disciplinar depende de aportes transdisciplinares que retornam através de conhecimento renovado e novas formas de intervenção. Os profissionais que operam neste campo deverão ser capazes de ultrapassar limites impostos pela doença, pelo estigma, pelas condições de vida adversas, para construir outros modos de operar, medianteas situações específicas que se apresentam.
Para Souza ${ }^{25}$, a criatividade e individualização nos cuidados em saúde mental têm se mostrado indispensáveis; porém, questiona as técnicas detrabalho. 0 autor defende a ampliação da projeção dos Centros de Atenção Psicossocial (CAPS) frente às políticas sociais de uma forma mais ampla, através da articulação e integração com as equipes de saúde da família, para a construção cotidiana de novos espaços. Traz a necessidade de ter clareza do referencial, para agenciar o processo de inovação das práticas, através da solidificação de princípiosfundamentais, para que não seincorra no erro de reproduzir as técnicas tão questionadas do modelo hospitalocêntrico ao se aproximar das comunidades.

Para Rotelli e colaboradores ${ }^{9}$, a base da instituição inventada a partir dos projetos de desinstitucionalização reside na ruptura da causalidade linear doença-cura, problema-solução e na reconstrução do objeto enquanto sujeito histórico. 0 autor ressal ta que as novas instituições deverão estar à altura da complexidade da tarefa deintervir na sua existência - sofrimento, remetendo ao processo da constante reconstrução deste sujeito.

Para queisto ocorra, há a necessidade da conformação de espaços coletivos, de lugares de reflexão crítica, de produção de subjetividade e constituição de sujeitos. Espaços coletivos são espaços concretos (de lugar e tempo) destinados à comunicação (escuta e circulação de informações sobre desejos, interesses e aspectos da realidade), à elaboração (análise da escuta edas informações) eà tomada de decisão (prioridades, projetos e contratos) ${ }^{26}$.

\section{Saúde M ental}

e a Estratégia (Programa) Saúde da Família

Diversos autores têm estudado a questão PSF e a reforma psiquiátrica $7,21,25,27-32$. Scóz e Fenili29 trazem um novo conceito de reforma intitulada de reforma substitutiva, que caracterizam por ser todo tipo de ação que visa a apresentar novas formas de cuidado da pessoa no seu processo de vida, através da reorientação do modelo assistencial, com a inclusão da família.

Tanaka e Lauridsen-Ribeiro ${ }^{32}$, com o objetivo de avaliar a atenção em saúde mental na atenção básica de saúde, realizaram um estudo comparativo entre os diagnósticos de problemas de saúde mental feitos pelos pediatras e os prováveis problemas de saúde mental identificados por meio da aplicação de um questionário padronizado aos pais. Os resultados encontrados apontam para a necessidade de mudanças na formação profissional do médico, otimizando sua capacidade de di- 
agnósticos precoces e encaminhamentos adequados, assim como a necessidade do aperfeiçoamento do processo de trabalho, no que tange ao atendimento em si, como na articulação entre as diferentes instâncias da rede.

Campos e Soares ${ }^{30}$, investigando a produção de serviços de saúde mental, descrevem as concepções de saúde mental de trabalhadores de diferentes serviços de saúde mental do município de São Paulo. No âmbito hospitalar, ambulatorial e da unidade básica de saúde, a concepção de saúdedoença é multifatorial e centrada no indivíduo, enquanto no Centro de Atenção Psicossocial (CAPS), a concepção aproximou-se da teoria da determinação social. Quanto ao processo de trabalho, o objeto recortado foi predominantemente o indivíduo doente e o sintoma da doença. Os autores concluem que o desafio é avançar no entendimento da concepção do processo saúde-doença e na formulação de processos de trabalho pautados no âmbito dos determinantes, através da compreensão de que a saúde mental também tem suas raízes no âmbito da reprodução social e não somente nos resultados do processo saúde-doença.

Consoli, Hirdes e Costa ${ }^{7}$ investigaram as características dos cuidados em saúde mental na região do Alto Uruguai, levando em conta as diretrizes do SUS e da reforma psiquiátrica. Os resultados apontam a inserção marginal dos profissionais na questão da saúde mental, embora a totalidade dos municípios disponham de Programas de Saúde da Família, as consultas clínicas como base da intervenção em saúde mental, a utilização da ambulancioterapia como solução para os casos agudos e crônicos, a centralização dos atendimentos no modelo do dano, da doença. Concluem que a questão da municipalização da saúde mental na região norte do Rio Grande do Sul é ainda incipienteesua concretização dependefundamentalmente da vontade política dos gestores, da capacitação técnica dos profissionais e da real inserção das ações de saúde mental no PSF.

$M$ achado e $M$ ocinho ${ }^{31}$ realizaram um estudo com o objetivo de mostrar os limites e possibilidades da atuação dos profissionais das equipes de PFS, em um município de pequeno porte do Rio Grande do Sul. Os resultados apontam que as ações em saúdemental concentram-seem uma clínica tradicional hospitalocêntrica e medicalizada, em razão de os sujeitos do estudo operarem com a lógica da exclusão e com conceitos psiquiátricos reducionistas e organicistas.

Tanto a Saúde Mental como a Estratégia de Saúde da Família têm apresentado novas modalidades de cuidado do processo de adoecimento, produzindo tecnologias diversas que propiciam um melhor cuidado. Essa é uma preocupação que envolve as pessoas e as relações. 0 cuidado requer envolvimento com o outro, está ligado à idéia de co-responsabilizar-se pelo outro, de envolver-se com o sofrimento do outro, de solidarizar-se com o outro. Então, pressupõe vincular-se a alguém e isso requer disponibilidade para o outro, para 0 inusitado, para a relação ${ }^{25}$.

$\mathrm{Campos}^{20}$, contextualizando a co-produção do singular no processo saúde-doença, a partir dos conceitos de clínica e saúde coletiva compartilhadas dentro de uma perspectiva de reformulação ampliada do trabalho em saúde, defende o método Paidéia: neste conceito, as mudanças são inevitáveis, mesmo quando em resistência ao novo. $\mathrm{N}$ este sentido, o método Paidéia tem a finalidade de aumentar o coeficiente de intencionalidade dos sujeitos, de compreender einterferir na ampliação, na co-responsabilidade pela constituição de contextos singulares. A co-produção do singular decorre da interação entre fatores universais e particulares, resultando em sínteses específicas. 0 singular é o contexto situacional, produto do encontro entre sujeitos em um dado contexto organizacional, cultural, político e social. Diferentes fatores (biológicos, psicológicos, socioeconômicos) exercem influência na constituição dos modos de vida dos sujeitos enos seus estados de saúdee de doença. A diferença está no grau com que cada fator atua em uma dada situação específica. 0 desafio consisteem captar esta variabilidadee propor projetos singulares adequados a cada situação.

Lancetti $^{28}$, ao relatar a experiência no Projeto Qualis, de São Paulo, que introduziu a saúdemental no Programa Saúde da Família, reforça que no PSF não é possível passar os casos, apesar do encaminhamento de pessoas para tratamentos mais complexos, em razão de esses pacientes morarem no mesmo bairro; assim, o vínculo ea continuidade exigem lidar com o sofrimento humano, processo para o qual a maioria dos técnicos ainda não está preparada, exigindo dos profissionais um trabalho psíquico e uma capacitação continuada.

As ações precisam estar onde as pessoas estão, inverte-se o paradigma asilar, o sujeito não é a especificidade individual, mas o conjunto de vínculos, de relações compartilhadas. A acessibilidade geográfica traduz-se pela facilidade deser atendido, a acessibilidade política traduz-se pela capacidade de planejar e decidir de modo participativo. A parceria PSF esaúdemental não quer dizer treinamento das equipes de saúde da família em procedimentos simplificados de psiquiatria. Requer, sobretudo, uma construção recíproca eresponsável deuma 
teoria, de uma prática e de uma ética, mediante 0 estabelecimento de um acordo político. Saúdemental e PSF implicam transformações profundas nas práticas do Estado, em todos os seus níveis ${ }^{27}$.

\section{Consideraçõesfinais}

M uitos avanços ocorreram com as experiências de desinstitucionalização. Entretanto, pensamosque, a despeito de muitos serviços que trabal ham sob a égide da reforma psiquiátrica em nosso país, há a necessidade de constantementeredimensionarmos o olhar para as práticas em curso, para que aos novos serviços correspondam as balizas propostas, no nosso caso, o referencial da reforma psiquiátrica italiana. Há que lembrar, também, que os dispositivos como os Centros de Atenção Psicossocial (CAPS) deverão se constituir como lugares de passagem; do contrário, sem esta revisão e crítica, a tendência dos novos serviços que trabaIham no contexto da reforma psiquiátrica poderá encaminhar-separa a institucionalização. Para que isto não ocorra, torna-se crucial a instrumentalização dos trabalhadores de saúde e de saúde mental, a sensibilização dos gestores de saúde e a permanente preocupação com a qualidade dos serviços oferecidos.

A inserção das ações de saúde mental no PSF constitui-se em estratégia adotada pelo M inistério da Saúde. A ênfase das ações de saúde mental no território constitui-se na própria essência da desinstitucionalização da psiquiatria. Para que efetivamente haja o deslocamento das ações de saúde mental para um contexto comunitário, a vontade política para a implantação de estruturas substitutivas à internação será crucial e, concretamente, irá redimensionar novos espaços para o sofrimento psíquico, a partir da produção de uma nova cultura de saúde/doença mental e das relações estabelecidas neste campo. Entretanto, estas ações devem transpor a centralização das ações no modelo biomédico, na doença, através de uma abordagem que articule tratamento, reabilitação psicossocial, clínica ampliada e projetos terapêuticos individualizados.

Cabe destacar a necessidade de investimento na instrumentalização dos profissionais para alavancar a inclusão do cuidado à saúde mental no SistemaÚ nico deSaúde, com vistasà reversão do modelo assistencial. A inserção das ações de saúde mental no PSF perpassa fundamentalmente a capacitação e apropriação de conceitos de clínica ampliada dos profissionais para a mudança do paradigma.

A reforma psiquiátrica brasileira, através da criação dos novos dispositivos em saúde mental, assim como através da inserção das ações de saúde mental na saúde pública, possibilita novas abordagens, novos princípios, valores e ol hares às pessoas em situação de sofrimento psíquico, impulsionando formas mais adequadas de cuidado à loucura no seu âmbito familiar, social e cultural. Os projetos de reforma não são homogêneos, as práticas são executadas conforme a concepção teórica dos trabal hadores de saúde mental. Concluímos, enfatizando que existem princípios orientadores gerais, mas que, em última análise, estão subordinados aos settings específicos onde ocorrem as práticas. 


\section{Referências}

1. Organização Mundial de Saúde/Organização Panamericana de Saúde. Declaração de Caracas. Conferência Regional para a Reestruturação da Atenção Psiquiátrica na América Latina no Contexto dos Sistemas Locais de Saúde (SILOS). 1990 nov 14; Caracas, Venezuela. Caracas: OM S/OPAS; 1990.

2. Brasil. Ministério da Saúde. Carta de Brasília. Princípios Orientadores para o Desenvolvimento da Atenção em Saúde M ental nas Américas. [acessado 2006 mar 07]. Disponível em: http://portal.saude.gov.br/portal/sas/ mental

3. Nicácio M FS. 0 processo de transformação da saúde mental em Santos: desconstrução de saberes, instituições e cultura [dissertação]. São Paulo (SP): Pontifícia Universidade Católica de São Paulo; 1994.

4. Bezerra Jr B. Cidadania e loucura: um paradoxo? In: Bezerra Jr B, Amarante $P$, organizadores. Psiquiatria sem hospício: contribuições ao estudo da reforma psiquiátrica. Rio de Janeiro: Relume Dumará; 1992.

5. Aguiar MGG. A reinvenção do ser enfermeira no cotidiano da Casa de Saúde Anchieta e núcleos de atenção psicossocial [dissertação]. São Paulo (SP): Escola de Enfermagem, Universidade de São Paulo; 1995.

6. Brasil. M inistério da Saúde. Legislação em Saúde M ental 1990 - 2004. 5a ed. [acessado 2007 set 05]. Disponível em: http://portal.saude.gov.br/portal/arquivos/ pdf/Legislacao.pdf

7. Consoli GL, Hirdes A, Costa JSD. Saúde mental nos municípios do Alto Uruguai, RS, Brasil: um diagnóstico da Reforma Psiquiátrica. Cienc Saude Colet [periódico na Internet] 2006 [acessado 2006 nov 23]. Disponível em: http://www.abrasco.org.br/cienciaesaude coletiva/artigos

8. Brasil. Ministério da Saúde. Base de dados do DATASUS. [acessado 2005 fev 26]. Disponível em: http:// www.datasus.gov.br

9. Rotelli F, Leonardis O, Mauri D, Risio C. Desinstitucionalização. São Paulo: Hucitec; 1990.

10. Amarante P. 0 homem e a serpente: outras histórias para a loucura e a psiquiatria. Rio de Janeiro: Fiocruz; 1996.

11. Goldberg J. Clínica da psicose: um projeto na rede pública. $2^{a}$ ed. Rio de Janeiro: Te Corá/Instituto Franco Basaglia; 1994.

12. Brasil. M inistério da Saúde. Dados referentes à reforma psiquiátrica: redução de leitos psiquiátricos e ampliação da rede extra-hospitalar. [acessado 2007 mai 20]. Disponível em: http://portal.saude.gov.br/portal/ arquivos/pdf/Reforma.pdf

13. Brasil. Portaria no 336 de 19 de fevereiro de 2002. Dispõe sobre a proteção e os direitos das pessoas portadoras de transtornos mentais e redireciona 0 modelo assistencial em saúde mental. Diário Oficial da União 2002; 20 fev.

14. Brasil. Portaria n 224 de 29 de janeiro de 1992. Dispõe sobre normas e diretrizes para os atendimentos hospitalares e extra-hospitalares. Diário Oficial da União 1992; 30 jan.

15. Brasil. Ministério da Saúde. Conselho Nacional de Saúde. Relatório Final da 3 a Conferência Nacional de saúde M ental. Brasília: Ministério da Saúde; 2002.
16. Bichaff R. 0 trabalho nos centros de atenção psicossocial: uma reflexão crítica das práticas e suas contribuições para a consolidação da reforma psiquiátrica [dissertação]. São Paulo (SP): Escola de Enfermagem, Universidade de São Paulo; 2006.

17. Oliveira AGB. A reforma psiquiátrica em Cuiabá/MT: análise do processo de trabalho das equipes de saúde mental [tese]. Ribeirão Preto (SP): Escola de Enfermagem de Ribeirão Preto, Universidade de São Paulo; 2003.

18. Arejano CB. Reforma Psiquiátrica: uma analítica das relações de poder nos serviços de atenção a saúde mental. Pato Branco: Rotta; 2006.

19. Saraceno B. Libertando identidades: da reabilitação psicossocial à cidadania possível. Rio de Janeiro: Te Corá/Instituto Franco Basaglia; 1999.

20. Campos GWS. Saúde Paidéia. 2ª ed. São Paulo: Hucitec; 2003

21. Cunha GT. A construção da clínica ampliada na atenção básica. São Paulo: Hucitec; 2005.

22. Merhy EE. Em busca do tempo perdido: a micropolítica do trabalho vivo em saúde. In: M erhy EE, Onocko R, organizadores. Agir em saúde: um desafio para o público. São Paulo: Hucitec; 1997.

23. M erhy EE. Saúde: a cartografia do trabalho vivo. São Paulo: Hucitec; 2002.

24. Almeida Filho N. Transdisciplinaridade e Saúde Coletiva. Cienc Saude Colet 1997; 2(1/2):5-23.

25. Souza AC. Em tempos de PSF... Novos rumos para Saúde M ental [dissertação]. Rio de Janeiro (RJ): Escola Nacional de Saúde Pública Sergio Arouca; 2004.

26. Campos GW. Um método para análise e co-gestão de coletivos. São Paulo: Hucitec; 2000.

27. Sampaio JJC, Barroso CMC. Centros de Atenção Psicossocial e Equipes de Saúde da Família: diretrizes e experiências no Ceará. In: Lancetti A. Saúde Loucura 7. 2a ed. São Paulo: Hucitec; 2001.

28. Lancetti A. Saúde Mental e Saúde da Família. In: Lancetti A. Saúde Loucura 7. 2ª ed. São Paulo: Hucitec; 2001.

29. Scóz TMX, Fenili RM. Como Desenvolver Projetos de Atenção à Saúde M ental no Programa de Saúde de Família. Revista Eletrônica de Enfermagem [periódico na Internet] 2003 [acessado 2006 nov 22]; 5(2):[cerca de 7 p.]. Disponível em: http:/www.fen.ufg.br/revista

30. Campos CMS, Soares CB. A produção de serviços de saúde mental: a concepção de trabalhadores. Cienc Saude Colet [periódico na Internet] 2003 [acessado 2006 nov 22]; 8(2): [cerca de 8p.]. Disponível em: http://www.scielo.br/scielo.php

31. Machado APC, M ocinho RR. Saúde M ental: um desafio no Programa de Saúde da Família. Boletim da Saúde 2003; 17(2):159-170 .

32. Tanaka OU, Lauridsen-Ribeiro E. Desafio para a atenção básica: incorporação da assistência em saúde mental. Cad Saúde Pública 2006; 22(9):1845-1853.

Artigo apresentado em 10/10/2007

Aprovado em 31/03/2008 